\title{
Korskolen vår
}

\author{
Av Kristin Vold Nese
}

$\ll$ Alle barn har en gnist $i$ seg, det som gjelder er å tenne den.» Roald Dahl

Kan det å synge gi oss livstolkning og livsmestring? Jeg mener det. Jeg har sunget helt fra jeg var ganske liten, nesten for jeg kunne snakke. Og sangen har gitt meg troens gave. Sangene har hjulpet meg gjennom livskriser. I trosopplaringen må vi tenke stort om sangene, de skal følge oss gjennom livet, $i$ glede og sorg. Sangene besitter også den egenskapen at vi kan huske dikt og tekster, så kjernetekstene sitter best når vi synger dem.

\section{KRISTIN VOLD NeSE, kantor og korskoleleder, e-post: korskoleleder@kirken.notteroy.no}

På Nøtterøy har kirken satset på sang i mange år, og Kirkens Korskole feirer 25-årsjubileum i 2015. Det er 225 sangere i Korskolen fordelt på 7 kor, 5 barne- og ungdomskor med til sammen 185 sangere. Det er de fire Kantorene på Nøtterøy og barne- og familiearbeider som sammen med omtrent 50 foreldre driver Korskolen. Korskolen er et samarbeid mellom de 3 menighetene på Nøtterøy, og korene synger i alle kirkene på omgang. De øver i en arbeidskirke og på et menighetshus.
Kantorene spiller i 4 kirker (ikke alle hver søndag), og vi har alle de kirkelige handlingene $\mathrm{i}$ våre stillinger. Jeg er korskoleleder og har hovedvekt på kor i min stilling. Vi har til sammen 3,6 kirkemusikalske årsverk.

\section{VÅR STRATEGI}

Kirkens Korskole er en del av Den norske kirke på Nøtterøy og har sin identitet i denne. Korskolen ønsker å bidra til at Den norske kirke oppleves som åpen og inkluderende. Korskolen er åpen for alle - uavhengig av kirkemedlemskap.

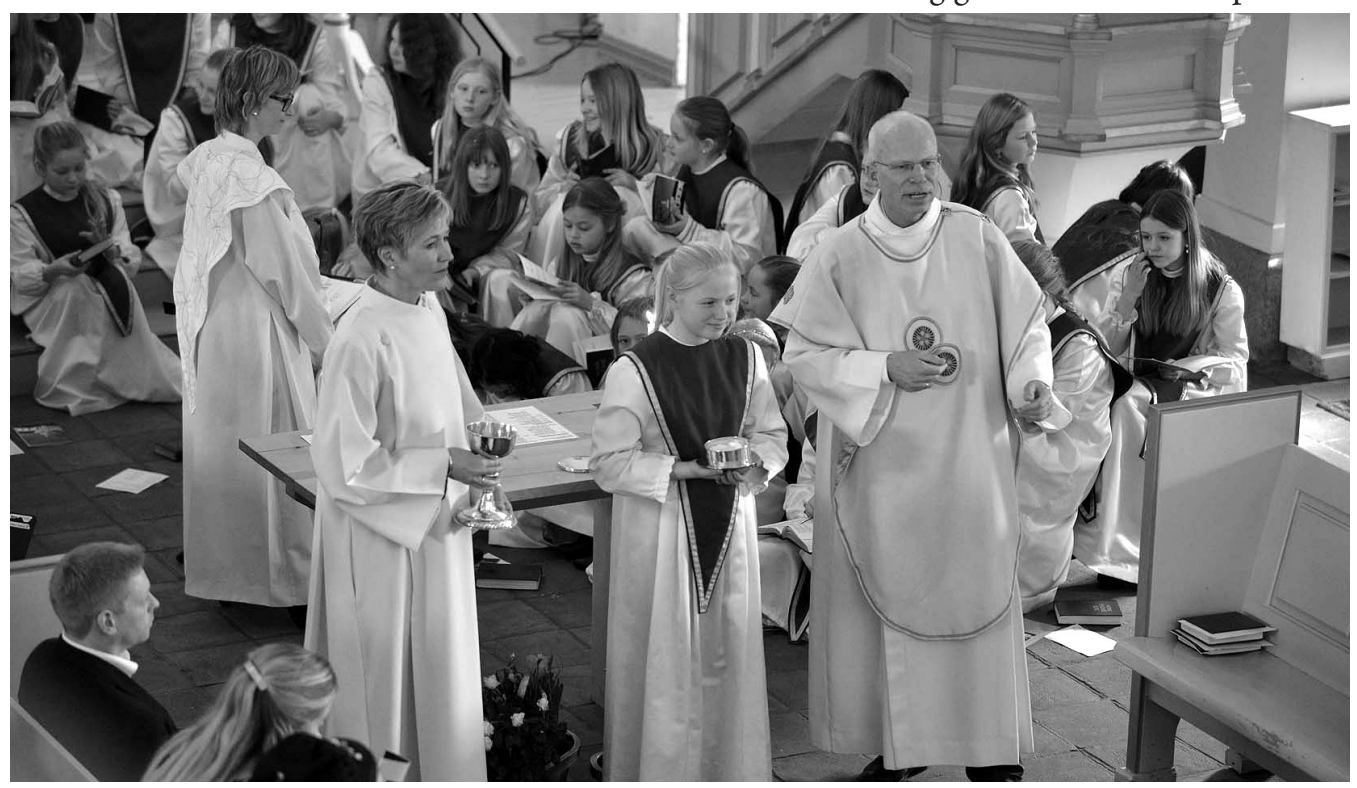


Guds tro på og respekt for det enkelte menneske skal prege virksomheten. Korskolen er bevisst på og åpen for at tro har mange forskjellige uttrykk, og vil virke til at mennesker kjenner rom for $\sin$ tro. Dette søkes nådd ved å forsøke å hente ut det beste i hver sanger - for så å møte mennesker med denne kvalitet i sin musikkutøvelse.

\section{Musikkarena}

Korskolen er et uttrykk for Kirkens satsing på musikk. Med sin musikkprofil ønsker Korskolen å prege kirkens virksomhet på Nøtterøy. Korskolen ønsker at musikken skal være tilgjengelig for alle og være arena for alle barn, unge og voksne som ønsker musikalsk tilhørighet.

\section{Kulturaktør}

I tillegg til å springe ut av Kirkens satsing på musikk på Nøtterøy, vil Korskolen betraktes som en sentral og selvstendig kulturaktør på øya. Korskolen vil tilby et musikkmiljø, formidle kunnskap om musikk og slik tilrettelegge for menneskers kjærlighet til musikk, blant sangere og tilhørere.

\section{Estetikk og mysterium}

Kirkens grunnleggende fundament og lære lar seg vanskelig forklare vitenskapelig. I sin formidling av sitt budskap vil kirken være avhengig av å finne berøringspunkter mellom guddommelighet og menneskelighet. Kunstens vesen er å «sette ord på det uuttalte». Kunsten - i ord og toner, i form og farge - kan åpne.

\section{Kvalitet i alle ledd}

Korskolen er opptatt av god kvalitet. For å få kvalitet i alle ledd må vi fokusere på kjerne-virksomheten. Denne starter med det viktigste i hele Korskolen: den enkelte sanger.

En god kommunikasjon mellom alle aktører i Korskolens arbeid vil være et godt grunnlag for at kvaliteten øker i alle ledd. Et godt lag er preget av at alle vet hva de skal gjøre, og at den enkelte opplever å mestre sine oppgaver. Innsats i Korskolen skal være forpliktende, men på et nivå som passer den enkelte. Det skal også være noe å strekke seg etter - hvor belønningen skal være å føle delaktighet for det gode resultat.

Ansvaret for den kunstneriske kvaliteten ligger hos Korskolens profesjonelle ledelse, mens mesteparten av alle omkringliggende oppgaver og aktiviteter ivaretas av frivillige.

$$
\text { Visjoner - tiltak }
$$

Korskolen er stolt av sin virksomhet - og vil i fremtiden fortsette arbeidet for å styrke den. $\ll$ I arbeidet med korskolen ønsker vi å hente ut det beste i hver sanger - for så å møte mennesker med denne kvalitet $i$ sin musikkutøvelse. Dernest ønsker Korskolen å bistå mennesker $i$ å anvende egne kvaliteter som del av kirkens tilbedelse. Korskolen er bevisst på at kvalitet ofte tilegnes gjennom strev, motgang, nederlag - slik og med livskvalitet. Korskolen ønsker å bidra til at mennesker kjenner at det er rom for hele livet deres $i$ kirke.»

Korskolen er bevisst på at kirkens skatter er de mennesker som kirken består av, samt de liturgier, salmer, tekster og sakramenter vi har fått overlevert gjennom kirkens liv - og at disse møtes i skjønn forening.

\section{HVORDAN JOBBER VI?}

Siden vi har 5 ulike kor fra 4-19 år, vil jeg beskrive hvordan vi jobber med de ulike gruppene, og ressursene som vi har til rådighet.

\section{Infantimus, gutter og jenter 4-6 år}

Koret Infantimus øver en time hver annen uke i menighetssalen (Aspirantkoret øver i kirkerommet), det ledes av barne- og familiearbeider, som også har med seg en pianist/gitarist.

Dette koret er preget av lek og mye vekt på at kroppen og sangen lever sammen. Mange enkle 
sanger med bevegelser. Mange av sangene har refreng/omkved. Barna synger mange kjente barnesanger som de synger i barnehagen/skolen (1.klasse). De synger også noen salmer, og sanger fra ulike musikalske genre. Vi har kjøpt små stoler til alle slik at de sitter godt.

Foreldrene til barn i denne aldersgruppen har det ofte trangt på ettermiddagen, og det er organisert en pølsekafé slik at alle kan komme tidlig og spise litt etter hentingibarnehage / SFO. Det er foreldrene som driver kafeen, og barna kaller koret for «Pølsekoret». Det er fint! Koret synger på gudstjenester 1-2 ganger per semester. Infantimus synger en fast avslutningssang: $\ll$ Kjære Gud ta min hånd».

\section{Aspirantkoret, for jenter i 2.-3. klasse og gutter i 2 . klasse}

De øver en time hver uke i kirkerommet. Kun dirigent, ikke fast repetitør, men av og til ved behov.

Når barnet begynner i 2. klasse, får de en større bevissthet om at de går i kor. De har i større grad valgt det selv. Og her jobber vi med at barnet får eierskap til sitt kor og sin gruppe. Nesten alle har gått i Infantimus, og de skal merke at de har blitt eldre og at sangene krever litt mer av dem. I dette koret presenteres barna for Solfa
(Do-Re-Mi), og de har egne korgensere! De skal merke at de har kommet $i$ et nytt kor.

Sangene er fremdeles enkle, mange gode refreng/omkved, og tekster som gir rom for undring. Mange av sangene har god rytme, og vi henter sanger fra alle genre, og mye fra den allmenne barnekulturen.

Aspirantkoret synger på gudstjeneste 2-3 ganger pr. semester og synger «Den dag du gav oss er til ende» som avslutningssang.

\section{Guttekoret - yngste gruppe, for gut- ter i 3. og 4. klasse}

De øver 55 min hver uke i en sal som har biljardbord og bordtennisbord. Her er vi dirigent og repetitør, det er avgjørende for å holde på fokus hos guttene.

De yngste guttene øver $55 \mathrm{~min}$. sammen med Eldste gruppe Guttekor, da er konsentrasjonen på topp, og de får med seg mye på den tiden. Den erfaringen vi har gjort i kor-arbeidet er at gutter gjerne har en tilnærming til læring som er mer fysisk enn jentene. Guttene synger et svært variert repertoar; Olsenbanden jr, Knutsen \& Ludvigsen, Queen med fler. De synger også mange salmer, nye og gamle, og flere ganske avanserte korsanger. Hvis guttene vil noe, kan

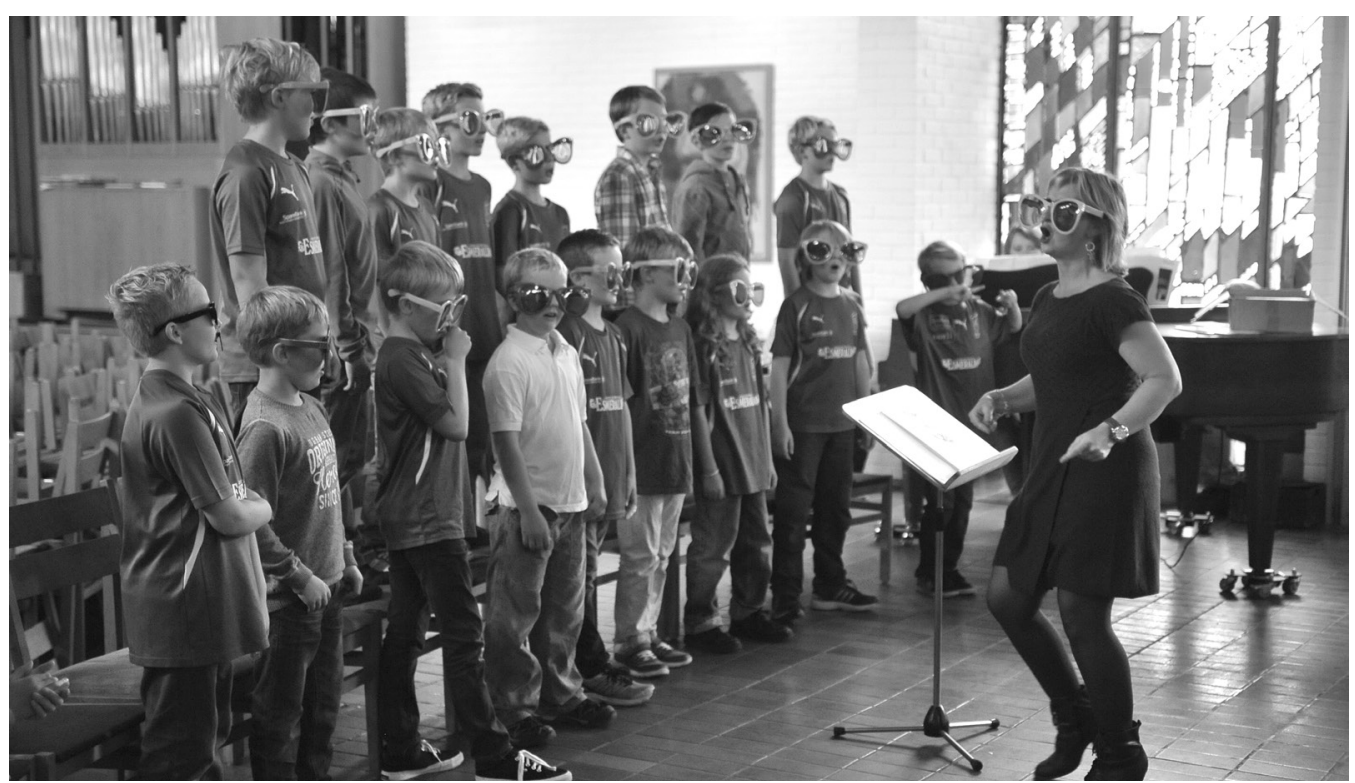


de få til utrolig mye. Særlig hvis de kan lese på mitt kroppsspråk at jeg liker sangen, kan sangen utenat, og har tro på at de også vil lære denne.

Det er alltid åpent $30 \mathrm{~min}$. før koret starter, da spiller guttene biljard og bordtennis. Guttene leker med alle, uansett om de er 2-3 år yngre, bare de vil spille.

Yngste gruppe ber Herrens bønn og synger «Gud vær oss nådig og velsign oss » som avslutningssang. (Sammen med eldste.)

\section{Guttekoret, eldste gruppe 5.-7. klasse}

De øver 1,5 time hver uke, 1. økt sammen med yngste gruppe guttekor. Dirigent og repetitør

I denne gruppen synger de også svært variert, men de har tydelig en lyst på mer klassisk repertoar, de synger f.eks. en vanskelig Beatleslåt og vil gjerne synge Pie Jesu, Panis Angelicus og annet klassisk repertoar. Det er viktig med variasjon, nytt og gammelt, rytmisk musikk, og mere lange linjer. Guttene vil gjerne bli gode. De ønsker å «rykke opp» en divisjon ...

I guttekoret har vi alltid foreldrevakt, alle foreldre må være til stede en gang pr. semester. Det er viktig at de voksne opplever hva vi driver med. Guttekoret synger på gudstjeneste 1-2 ganger per semester. Da synger de sammen med yngste gruppe, og fremstår som Nøtterøy Guttekor utad, men guttene vet godt om de er i eldste eller yngste gruppe, det handler mye om å bli som de eldste. Derfor er det helt avgjørende at vi har med oss gode forbilder som hjelpedirigenter fra Ungdomskantoriet. Det er gutter fra 16 til 18 år som synger bra, som har gode sosiale antenner, og som blir alle guttenes helt!

Eldste gruppe synger «I dine hender Fader blid $\gg$ som avslutningssang.

Guttekoret har kapper og Puma fotballtrøyer med tall og navn på ryggen.
Barnekantoriet, jenter i 4.-7. klasse

De øver hver uke i 1,5 time i en arbeidskirke slik at vi kan ha pause med plass og lage ting. Dirigent og repetitør

Det kan være en utfordring å finne «de rette» sangene i dette koret. Jentene vil synge musikal og vakre melodier, og det er mye godt stoff å velge blant. Vi har jo mange flotte salmer, og Disney er en gave til alle dirigenter. Det er mye godt å velge i. Det er gode fortellinger også. Jentene synger også klassisk korrepertoar som «Sound The Trumpet» og «Ave Maria». I dette koret er det 50 jenter, og vi har i flere år jobbet med å bygge et klima hvor 7. klasse har en helt egen status. De er faddere, de synger alltid 2. stemme, og jeg tar dem med ut av øvelsen $15 \mathrm{~min}$. hver annen gang mens de andre øver med repetitøren. Det er en viktig faktor, de gleder seg til å komme i 7. klasse. Jeg jobber også mye med å bygge en forståelse av at de beste er de som ser andre, og bryr seg om andre, og at alle er viktige $\mathrm{i}$ vårt kor.

Jeg må jobbe mer for at jentene leker med noen de ikke kjenner, og de trenger mer for å bli kjent på tvers av alder. Det er også foreldrevakter i dette koret, på samme måte som på guttekoret.

Barnekantoriet synger på gudstjeneste 2-3 ganger per semester. De har korkapper.

Siden vi øver i et kirkerom, tenner jeg alltid et lys i globen, og de kan komme med ønsker om bønneemner. Det må de si til meg i pausen, slik får vi snakket om temaet, det er ikke alt som egner seg for alle. Jeg ber en bønn, tenner lys, vi ber Herrens bønn og synger «Herren velsigne oss, Herren bevare oss ».

\section{Ungdomskantoriet, gutter og jenter fra 8. klasse til 19 år}

De øver 1,5 time hver uke på et menighetssenter hvor det er kjøkken. Dirigent og repetitør.

Ungdomskantoriet kommer etter skolen, de lager og spiser middag sammen, og har sosi- 
alt sammen fra etter skolen til de begynner å øve klokken 16.00. De kommer på ulike tider, og noen spiser og noen spiser ikke, men alle må være med på å handle, lage og rydde to ganger per semester sammen med sin faddergruppe. Faddergruppen ledes av en av de eldste, som regel en russ.

De har stemmeøving etter koret en gang per måned. Ungdomskantoriet har et eget styre med sangere fra koret. De gjør veldig mye, de organiserer alt med maten, de lager sosiale «happenings», de hjelper med notene og er søylene i koret. Det er rift om å bli med i styret. Det fungerer veldig fint å ha gutter og jenter sammen, det blir liv og latter, og mye moro. Guttene synger tenor og bass når de er kommet inn i stemmeskiftet, og før det synger de alt. Ungdomskantoriet synger alle genre, de jubler over både Beatles og
Hallelujakoret, og de blir ganske stilsikre. De trenger variasjon, og vi bruker tid på å snakke om at vi liker ulike ting, og at alle må gi og ta. Dette koret synger og litt gospel, og trives med det. Men ikke for lenge, da blir de lei.

Det er 19 gutter og 45 jenter i koret. Det året de er konfirmanter, er de Korskolekonfirmanter og går på kor som konfirmantundervisning. Det er veldig bra fordi dette året er et brytningsår, og de må «holde på koret» for å få godkjent konfirmantåret. Og de blir værende i koret etter konfirmasjonen.

Ungdomskantoriet drar på utenlandsturer hvert annet år, de har sunget i St. Pauls og Notre Dame. Hele koret synger på 3 gudstjenester pr semester, og de synger med faddergruppen sin en gang i året i tillegg. De har korkapper.

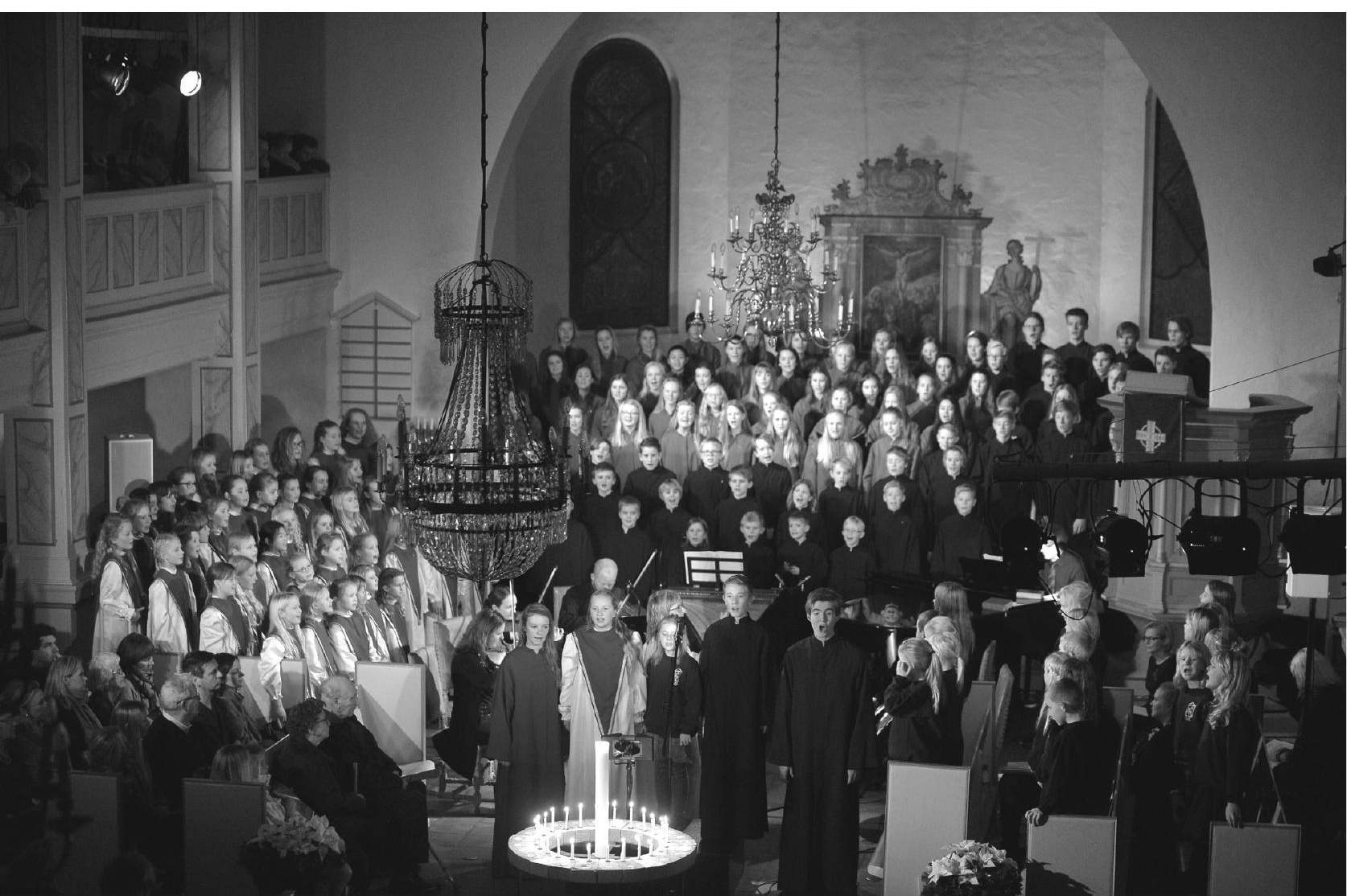

Foto: Gudmund Nese 


\section{SAMHØRIGHET}

Alle korene i korskolen har store konserter sammen, da kjenner vi fellesskapet og samhørigheten. Det er viktig av og til å være mange. Det er flere av sangerne i Korskolen som har ønsket å jobbe i kirken, 3 av sangerne har de siste ti årene utdannet seg til kantor, og en har blitt trosopplærer.
Det er et felles styre for alle barne- og ungdomskorene i Korskolen. Og vi har mange komiteer hvor foreldrene er med kort eller lang tid. Vi har komiteer for mat, løfte og bære, lys (korskolen eier en lysrigg), basar, kostyme/ søm, pynt, plakat og valg. Vi utkommanderer aldri noen til å være med, og vi vil bare ha med de som har lyst.

Det har vi greid i 25 år!

«Vokt meg som din øyensten, skjul meg i skyggen av dine vinger $\gg$ Salme 17,8. 